\title{
Redesign, Development and Construction of Powered Burner Head
}

\author{
Hosni I. Abu-Mulaweh*, Donald W. Mueller \\ Purdue University Fort Wayne, Fort Wayne, IN 46805, USA
}

\begin{abstract}
This paper presents the redesign of a burner mixing head that used on High Static Gas burner (HSG) product to mix the gas and air mixture before it is ignited. This burner operates in firing range of 60,000-400,000 Btu/hr. The objective of redesigning the burner mixing head is to improve the overall performance of the HSG burner. This design project deals with the mixing head of a powered gas burner utilizing both natural and propane gases. The mixing head's function in a powered gas burner is to initiate the fuel gas into an air stream. The redesigned burner mixing head increases combustion efficiency by $3 \%$ compared to the original burner head. This new burner mixing head operates within a wider range of excess air of $5 \%$ on both the lean and rich side while still igniting reliably and keeping the CO levels under 400 ppm. The redesigned burner mixing head design meets all the criteria of the American National Standards Institute ANSI Z21.17 standard for domestic gas conversion burners. The redesigned burner mixing head was machined out of 304 stainless steel which makes the burner head have corrosion resistant properties this includes using corrosion resistant fasteners.
\end{abstract}

Keywords: Burner Head, Design, Combustion

\section{Introduction and Background}

A manufacturer of gas and oil burners for commercial cooking and furnace applications has requested assistance in the redesign of a burner mixing head of High Static Gas burner (HSG) product line to mix the gas and air mixture before it is ignited. This burner operates in firing range of 60,000-400,000 Btu/hr. The current burner mixing head is shown schematically in Fig. 1.

The purpose of the burner head is to supply heat to an appliance. It accomplishes this by delivering a gas, natural gas or propane, to the burner head. Inside the burner head the gas is mixed with air that is being forced down the air tube. The mixed gas/air leaves the burner head from the sides entering the gas/air mixture zone, as shown in Figure 1. At that point, further mixing occurs from the air being forced down the sides of the air tube. Simultaneously, an electrode generates a spark that lights the gas at one of the burner ports, then ignition occurs, and a single flame kernel will light the air/gas mixture coming out of the other burner ports. The air on the sides of the air tube will be continually supplied so that it brings the kernels of the flames past the burner head. Another source of air passes through the burner head, this air does not mix with the gas, but is used to help complete the combustion process. This is accomplished by five cylindrical tubes that are attached to end on the burner mixing head.

Excess air is the air that is supplied to the combustion process beyond the amount of air required for a stoichiometric process [1]. The stoichiometric process is the theoretical fuel/air ratio where there is no left over oxygen in the products. The $\mathrm{CO}_{2}$ concentration is at its highest when it is at the ultimate $\mathrm{CO}_{2}$ value, as shown in Fig. 2. The closer that the burner can operate near this point the more efficient the combustion process is. The combustion efficiency of the burner head is used to evaluate the performance of the unit.

In the current burner head, shown schematically in Fig.e 3, the gas and air streams enter their respective inlets, and the streams go through a sudden expansion as they enter into the mixing chamber. This sudden expansion creates a disturbance in the flow that will help mix the gas and the air before it exits out of the burner ports. The sudden expansion will also cause the

${ }^{*}$ Corresponding author. Tel.: +260-481-6357

Fax: +260-481-5734; E-mail: mulaweh@pfw.edu

(C) 2018 International Association for Sharing Knowledge and Sustainability

DOI: 10.5383/ijtee.16.01.002 
velocities of the gas and air to decrease while the pressure in the chamber will increase. This increases the mixing time to help create a more thorough mixture. The burner exit ports are sized in a way to promote flame stability.

\section{System Requirements and Specifications}

The design process that was employed in this research project is the one outlined by Bejan et al. [2] and Jaluria [3]. The first essential and basic feature of this process is the formulation of the problem statement. The formulation of the design problem statement involves determining the requirements of the system, the given parameters, the design variables, any limitations or constraints, and any additional considerations arising from safety, financial, environmental, or other concerns.

The redesigned burner mixing head must be compatible with the existing burner body and must not change the shape of the burner to accommodate it and must meet the following requirements and specifications:
- Increase the combustion efficiency of the burner mixing head by at least 3\% while still maintaining clean combustion.

- Ability to operate at a wider range of excess air while still igniting reliably. The current burner mixing head under the specifications outlined above operates from 20 to 55\% excess air. The redesigned burner mixing head is to increase the operating range to 15 to $60 \%$ excess air.

- The burner mixing head must pass all tests in ANSI Z21.17 Standard for Domestic Gas Conversion Burners [4]. The CO levels must be kept under 400 ppm.

- The material used for the burner mixing head must be corrosion resistant and high temperature resistant.

- The burner mixing head must operate both with natural and propane gases without changing parts of the burner mixing head.

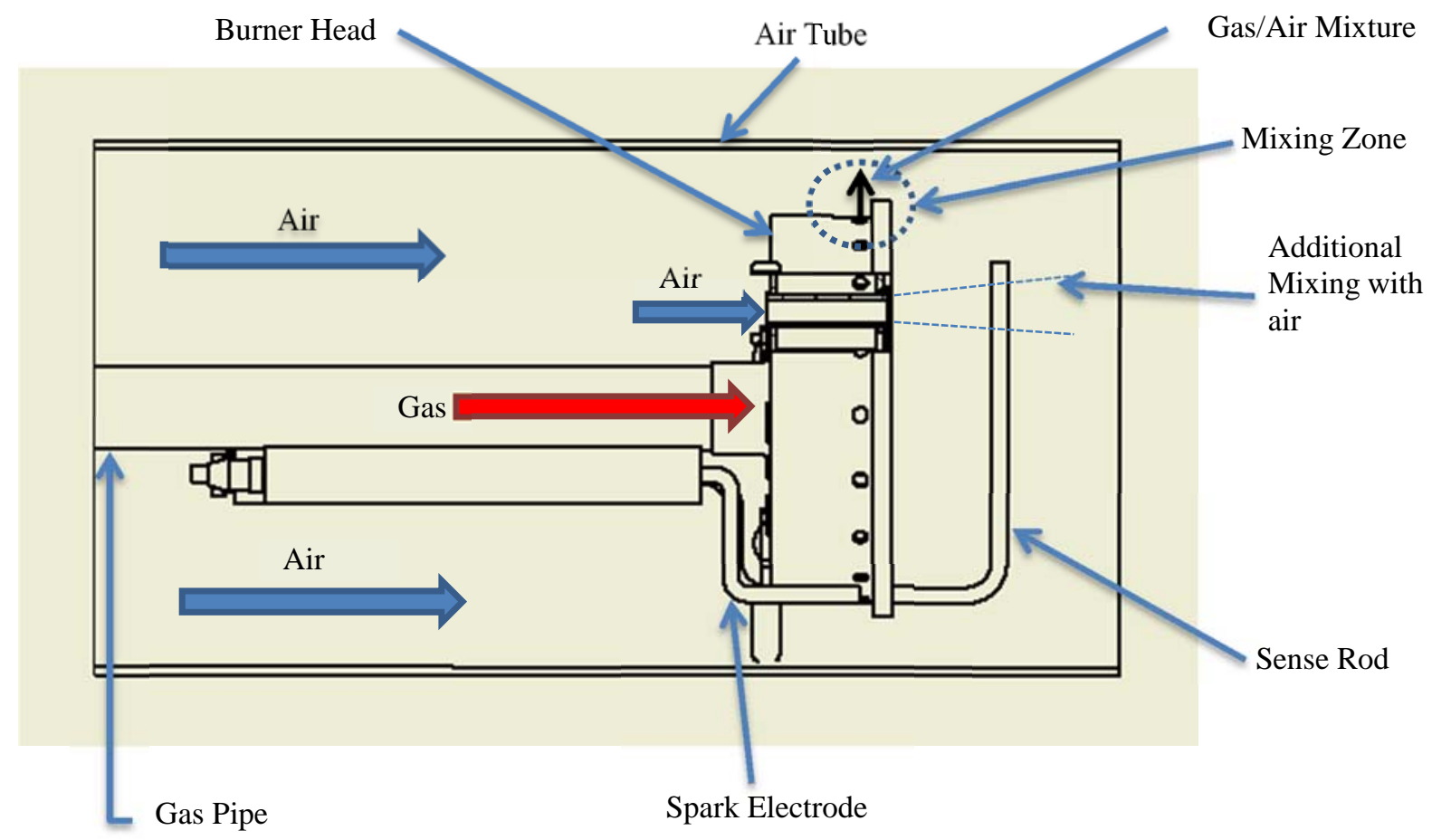

Fig. 1. Cross-section of current design and flow paths 


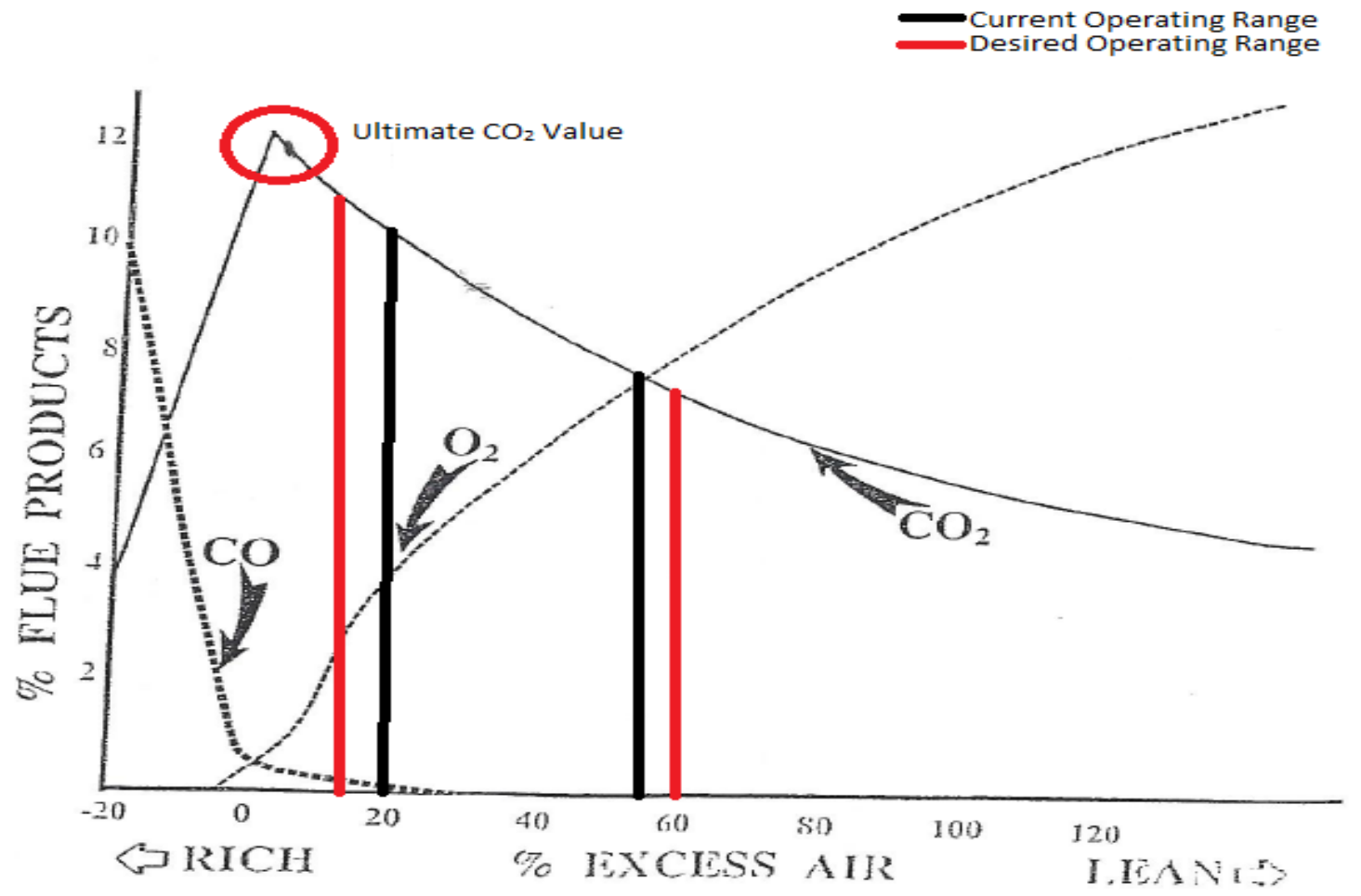

Fig. 2. Variation of the flue products with excess air

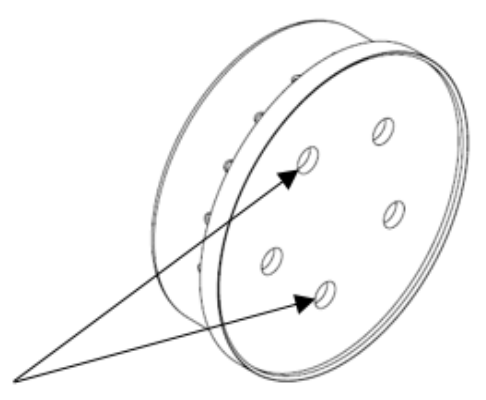

Air Flow Tunnels Isometric View

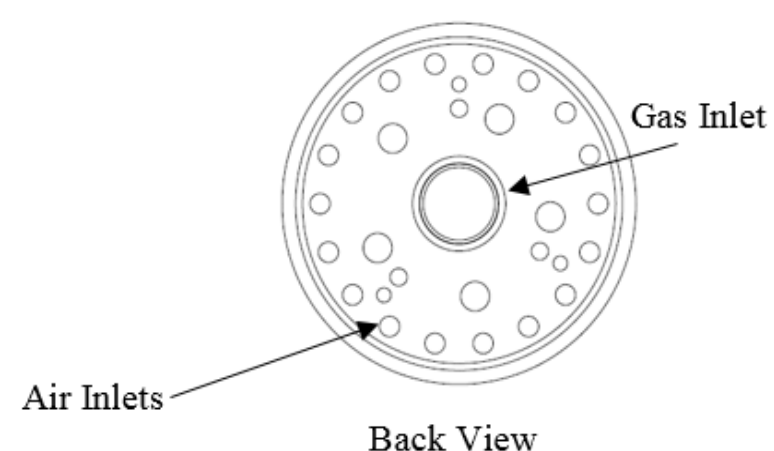

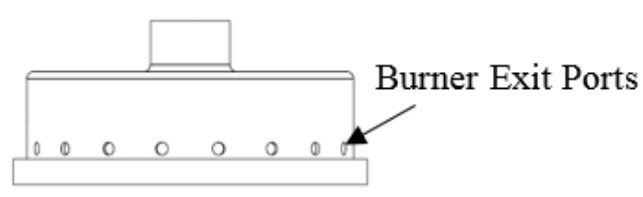

Side View

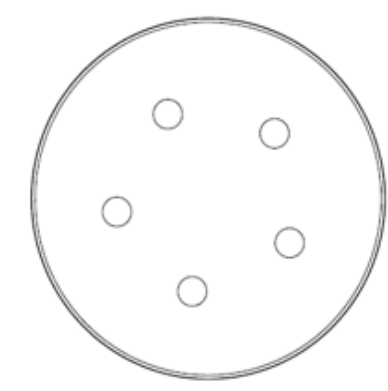

Front View

Fig. 3: Schematic of the current burner head design 


\section{Redesigning Burner Mixing Head}

Several designed concepts were generated and evaluated. A "Plate Burner Head" concept was chosen (Fig. 4). In the figure: $\mathrm{D}_{\mathrm{p}}$ is the burner ports diameter, $\mathrm{N}_{\mathrm{p}}$ is the number of burner ports, $\mathrm{Dg}_{\mathrm{g}}$ is the gas outlet diameter, and $\mathrm{N}_{\mathrm{g}}$ is the number of gas outlet. In this design concept, gas flows through the pipe and exits into the air stream at a $90^{\circ}$ angle. Because the gas and air are meeting at an angle, impingement will occur, which promotes mixing. Mixing time can be increased due to the mixing length. This mixing determines where the gas outlets are located along the gas pipe. The diameter and number of gas outlets will also influence the mixing efficiency of the design. The mixture will be forced onto the plate, due to the air stream, and pass through the burner ports. The size, quantity, and location of these burner ports is important, this will decide how stable the flame is.

The Plate Burner Head design concept has two important phases, the mixing phase and the combustion phase. The mixing phase is where the gas stream is injected into the air stream at a $90^{\circ}$ angle. The combustion phase occurs after the gas/air mixture passes through the burner plate, and then the mixture is ignited. Each phase needed to be optimized for performance and efficiency.

The optimization of each phase was determined by its mixing capabilities, and the average velocity of the mixture after it exited the burner ports. SolidWorks Flow Simulations [5] were used to analyze the gas/air ratios and the fluid's velocity at the locations of interest in the system.

Three inputs had to be specified, those were the fluids, inlet boundary conditions, and the outlet boundary condition. There was two different fluids used in this system, methane and air. The gas traveled through a pipe and the air traveled through a tube surrounding the pipe. There are two inlets, thus two inlet boundary conditions that needed to be specified. Experimental data provided by the manufacturer helped determine the gas volume flow rate and excess air for the case of HSG burner fired at 200,000 and 400,000 Btu/hr. The combustion equation gave a ratio between air and gas, which was used to find the volume flow rate of air at the inlet. Since the air/gas mixture has already combusted by the time it exits the burner ports, there is only one outlet boundary condition. Typically the velocity of the products of combustion are unknown as they leave the air tube. However, the pressure of the chamber that the burner fired into is known, this was called the back pressure that pushes back on the flame as it traveled through the combustion chamber. For typical applications of a HSG burner there is a positive gauge pressure of 0.5 inch $\mathrm{H}_{2} \mathrm{O}$ at the outlet of the air tube. This value is the average case but there is always the chance that the burner will be placed in a situation where the back pressure will be higher. A design factor of 2 is typically used in the gas industry to prevent flashback. The outlet boundary condition that was used for simulations was a pressure of 1 inch $\mathrm{H}_{2} \mathrm{O}$.

The plate's purpose is to give the flame a point to anchor to. This section relates to flame stability. Where the anchor point will occur was determined by the mixture's velocity as it left the burner head's ports. If the velocity of the gas/air mixture was less than the speed of the flame front then the flame stabilization point will move closer to the plate. This would make it more likely for flashback to occur. This phase of the design is to find a flame stabilization point that will not cause the flame to flashback or cause dirty combustion. Dirty combustion is when certain emissions are beyond an unacceptable threshold set by ANSI Z21.17. This can occur if the flame stabilization point moves, due to lifting. Lifting can cause the tip of the flame to impinge on a cold surface in the combustion chamber. When the flame hits the cold surface it quenches the flame and it does not allow the combustion process to complete. This typically results in higher concentrations of $\mathrm{CO}$ in the products of combustion. The velocity exiting the burner ports will be compared in order to find the ideal plate design.

The shape of the burner ports was chosen to be circular, this decision was based on past engineering judgement. Different shapes have been used in the past where the burner ports had different geometries with sharp corners. These sharp corners would induce stress concentrations that would cause cracking in the burner head material. This is due to the thermal cyclic stress that the burner head would be exposed to over time. Therefore, circular ports are the best decision for the port geometry because they do not have these sharp edges for the cracks to propagate to other stress concentrations. Another reason is that circular holes are easier to machine with standard drill bit sizes.

The diameter of these burner ports was not a design parameter. The quench diameter that was chosen for the burner ports was 0.11 inches. The quench diameter is a critical diameter used in the design of gas burners. It is the largest diameter that the burner ports can have and still resist flashback. Faster burning gases typically have smaller limiting quench diameters than slower burning gases. Propane is typically a faster burning gas, than methane due to the increased carbon content in the fuel, because of this the quench diameter chosen was based off of propane.

The two parameters had to operate within a certain range. This range is due to port loading of the burner plate. Port loading is the gas input rate divided by the total area of the burner ports. Its units are Btu/hr-in², port loading is not an exact science, but it is useful for predicting the required number of holes depending on the desired port loading. Port loading is related to the number of holes as the following:

$$
\frac{\text { Gas Input rate }\left[\frac{B t u}{h r}\right]}{\text { Desired Port loading }\left[\frac{B t u}{h r-i n^{2}}\right]}=A_{\text {total }}
$$

Where $A_{\text {total, }}$ is the total burner port area, which is equal

$$
A_{\text {total }}=N_{p} *\left(\frac{\pi}{4}\right) *\left(D_{\text {quench }}\right)^{2}
$$

Where $\mathrm{D}_{\text {quench }}$ is the quench diameter. Since the quench diameter was fixed this allowed the required number of holes to be calculated for various port loadings.

The final results for all parameters are:

\begin{tabular}{|c|c|c|c|c|}
\hline$D_{\mathrm{g}}$ (in.) & $\mathrm{N}_{\mathrm{g}}$ & $\mathrm{L}_{\text {mix }}$ (in.) & $\mathrm{N}_{\mathrm{p}}$ & $\mathrm{D}_{\text {plate }}$ (in.) \\
\hline 0.125 & 8 & 2.0 & 30 & 3.0 \\
\hline
\end{tabular}

A prototype of the redesigned burner mixing head was assembled and it is shown in Fig. 5. 


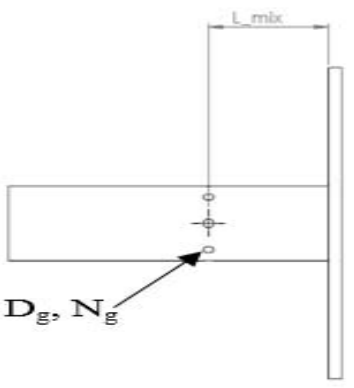

Side View

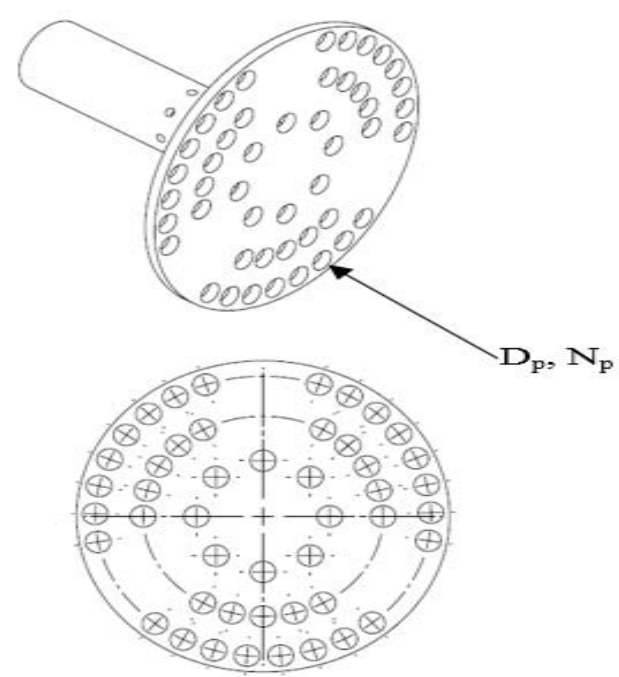

Front View

Fig. 4: Schematics of the plate burner head design concept.

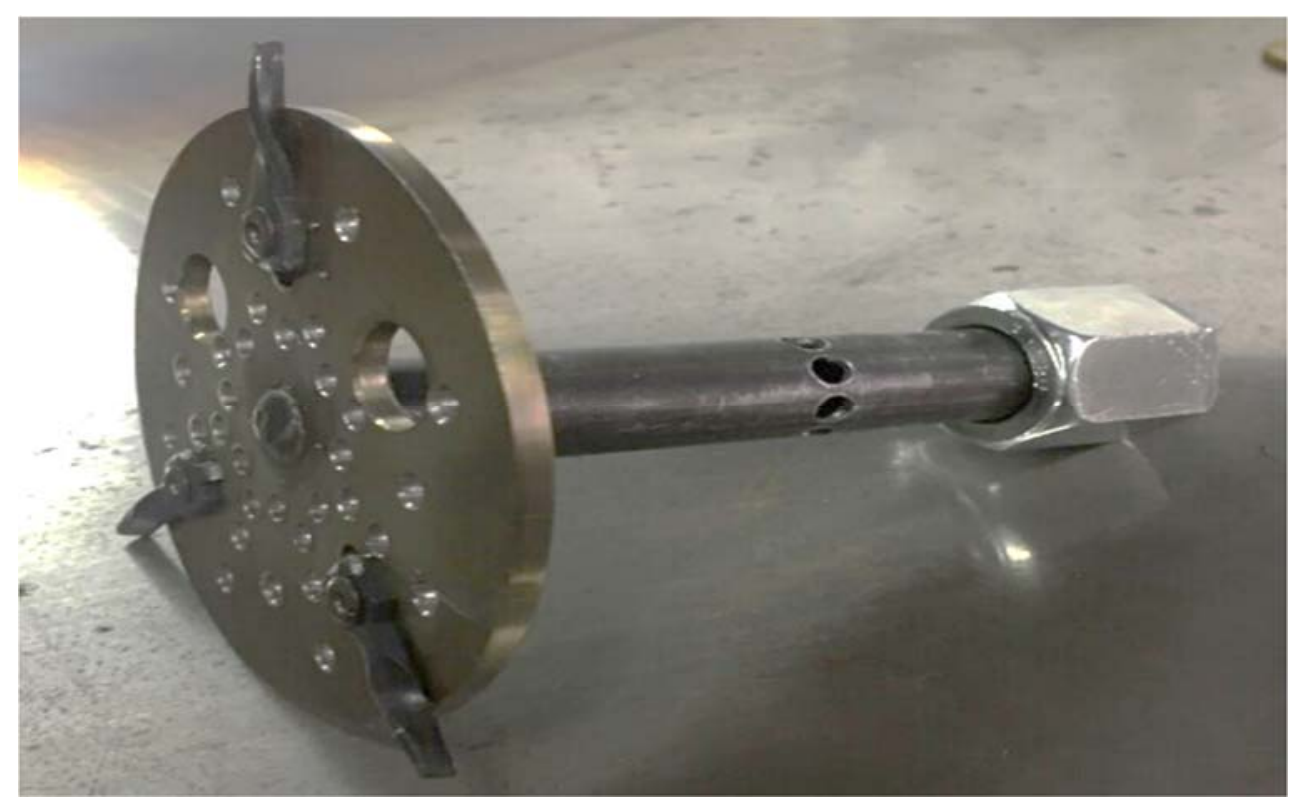

Fig. 5: A prototype of the redesign burner head

\section{Testing and Sample Results}

The prototype of the redesigned burner mixing head was subjected to several tests to determine the achievement of the requirements. A Testo 330-1L combustion analyzer was used to measure the; $\% \mathrm{CO}_{2}$, \% Excess Air, $\% \mathrm{O}_{2}$, and parts per million of CO.

The data from the analyzer is then used to calculate the combustion efficiency and $\mathrm{CO}$ air free.

Combustion efficiency is be calculated from:

$$
\eta_{\text {combustion }}=\left(\frac{\mathrm{CO}_{2} \text { measured }}{\mathrm{CO}_{2} \text { ultimate }}\right) * 100
$$

$\mathrm{CO}_{2}$ ultimate is the maximum value of carbon dioxide that can occur in a stoichiometric reaction. It is a constant that varies for different gases or other fuels. For natural gas the $\mathrm{CO}_{2}$ ultimate value is $11.73 \%$, this will be used since natural gas was chosen as the test gas for these experiments.

$\mathrm{CO}$ air free (COAF) is calculated from:

$$
\mathrm{COAF}=\mathrm{CO} * \frac{\mathrm{CO}_{2} \text { max }}{\mathrm{CO}_{2} \text { measured }}
$$

The reason this quantity needs to be calculated is because when the analyzer draws in a $1 \mathrm{~mL}$ sample from the exhaust, it also 
draws $5 \mathrm{~mL}$ of air to dilute the sample. The analyzer does this to increase the life of the sensors that it uses to measure the products of combustion. The COAF is the true value of how much carbon monoxide there is in a sample. It uses the $\mathrm{CO}_{2}$ ratio to take into account the amount of oxygen in the sample.

\section{Test \#1: Steady state operation}

The prototype of the redesigned burner mixing head was first tested to determine the time period needed for the combustion process to reach steady state. The results showed that it took 1.5 minutes for the combustion process to reach steady state.

Test \#2: Verification of the achievement of combustion efficiency and excess air range requirements

The purpose of this test is to determine the combustion efficiency and the excess air range that each burner mixing head can obtain while maintaining clean combustion. Both the original and redesigned burner mixing heads were tested and the results are presented in Fig. 6. In this figure, $\mathrm{CO}_{2}$ and $\mathrm{O}_{2}$ is expressed as a volume percentage, and they are plotted on the primary vertical axis, on the left. The $\mathrm{CO}$ air free values are expressed in parts per million (ppm) and they are plotted on the secondary axis, on the right. $\mathrm{CO}_{2}$ and $\mathrm{O}_{2}$ meet at a point and the $\mathrm{CO}$ levels increase as the amount of excess air is increased. It can be seen that the redesigned burner head spans further out in both the low and high side of excess air, represented by the solid red line, the original burner head, represented by the dashed blue line. This shows that the excess air range for the redesigned head is greater.

Efficiency calculations indicate that the original design had a max efficiency of $82.8 \%$ and the redesigned head had an efficiency of $85.8 \%$. The newly designed head is $3 \%$ more efficient than current burner head.

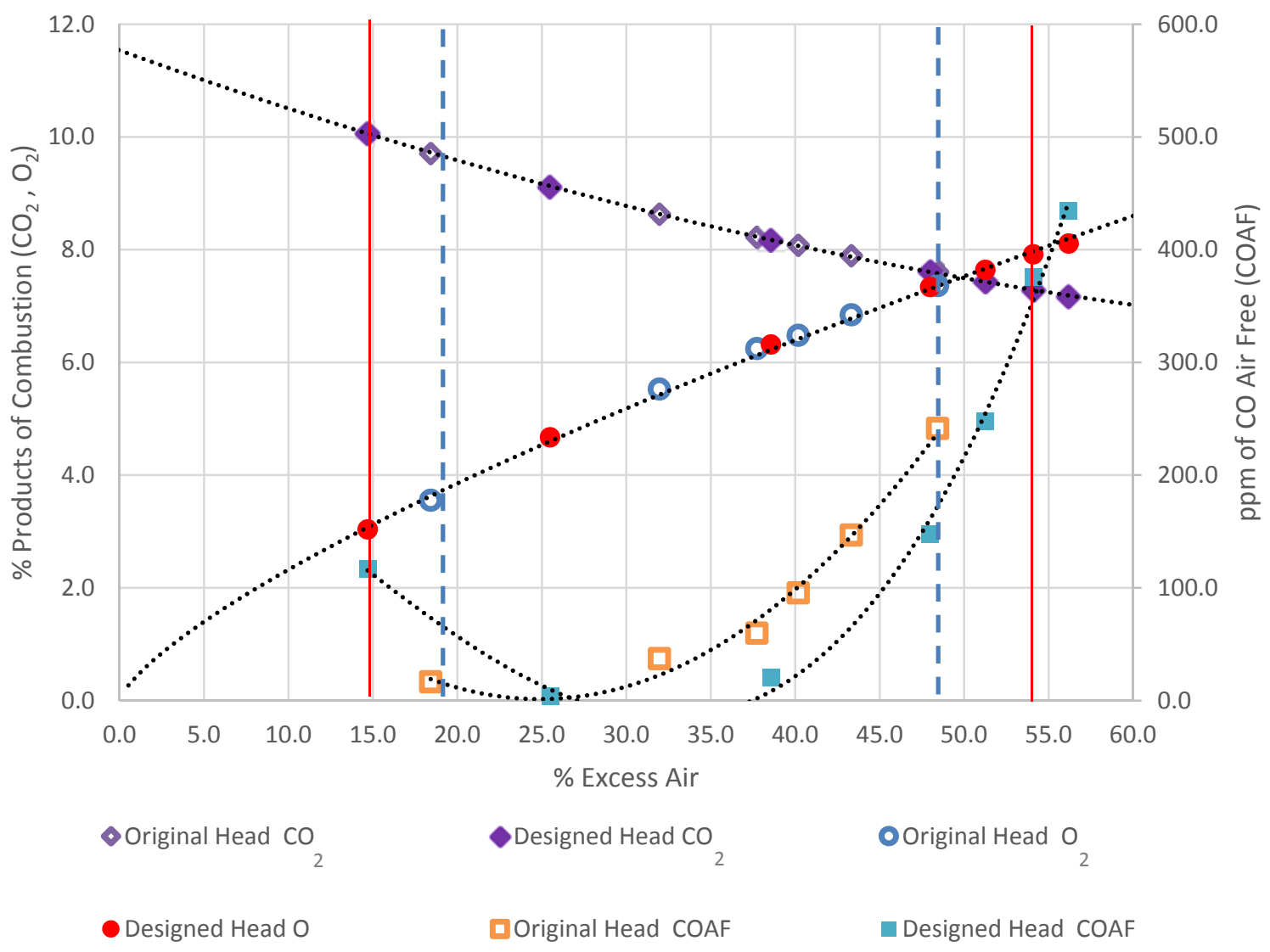

Figure 6: Verification of the achievement of combustion efficiency and excess air range requirements.

Test \#3: American National Standards Institute (ANSI) safety $\underline{\text { tests }}$

Tests were performed on the redesigned burner mixing head to validate its compliance with ANSI Z21.17, Sections 2.4.1 and 2.4.2. These ANSI standards test tests the performance of the burner at various adverse conditions that could occur while the burner is operating in the field. The goal of these tests is to ensure that no matter what adverse conditions occur; the burner head will still maintain clean combustion.

The test results show that:

- The COAF is well below 400 ppm at 200,000 and 400,000 $\mathrm{Btu} / \mathrm{hr}$, so the burner head is compliant with section 2.4.1 of the ANSI Z21.17 standard.

The burner head is compliant with reduced voltage/normal inlet pressure test in section 2.4.2 of the ANSI Z21.17 standard. 
References should be numbered consecutively throughout the paper using Arabic figures in brackets: [1], [2], etc. and collected together in a section headed "References" at the end of the paper. Reference to journal articles [1], textbooks [2], papers in conference proceedings [3], chapters in books [4], monographs [2], technical reports [5] and theses [6], should provide sufficient information as in the samples.

\section{Conclusion}

SolidWorks simulations were used to redesign a burner mixing head for high static gas burner utilizing both natural and propane gases is redesigned. The redesigned burner mixing head. The combustion efficiency of the redesigned burner mixing head is increase by $3 \%$ compared to the original burner head. This redesigned burner mixing head operates within a wider range of excess air of $5 \%$ on both the lean and rich side while still igniting reliably and keeping the CO levels under 400 ppm.

\section{References}

[1] C. Borgnakke, R.E. Sonntag, "Fundamentals of Thermodynamics”, John Wiley \& Sons, Inc., New York, 2013.

[2] A. Bejan, G. Tsatsaronis, M. Moran, "Thermal Design \& Optimization”, John Wiley \& Sons, Inc., New York, 1996.

[3] Y. Jaluria, "Design and Optimization of Thermal Systems”, McGraw-Hill, New York, 1998.

[4] “ANSI Z21.17a-2008/CSA 2.7a-2008 - Addenda 1 to ANSI Z21.17-1998/CSA 2.7-M98, Domestic Gas Conversion Burners”, 2014, from http://shop.csa.ca/en/canada/gas-fired-domestic-andcommercial-heating-equipment-and-airconditioning/ansi-z2117a-2008csa-27a-2008r2014/invt/27011152008amda.

[5] SolidWorks Edition 2016, 